\title{
Temporal and Spatial Vegetation Index Variability and Response to Temperature and Precipitation in the Qinghai-Tibet Plateau Using GIMMS NDVI
}

\author{
Tao Wang ${ }^{1 *}$, Meihuan Yang, Suijun Yan², Guangpo Geng¹, Qihu Li ${ }^{1}$, Feng Wang ${ }^{3}$ \\ ${ }^{1}$ College of Geomatics, Xi' an University of Science and Technology, 58 Yanta Road, Xi'an, China \\ ${ }^{2}$ Shandong Branch of China National Geological Exploration Center of Building Materials Industry, \\ 32 Shanda North Road, Jinan, China \\ ${ }^{3}$ Ocean Wood Mapping Information Technology Limited Company, 69 South Second Ring Road, Xi'an, China
}

Received: 30 December 2019

Accepted: 18 April 2020

\begin{abstract}
The vegetation of the Qinghai-Tibet Plateau (QTP) is fragile and vulnerable to global and regional climate change. This paper analyzed the temporal and spatial variability of NDVI and response to temperature and precipitation in the QTP from 1982 to 2015. The results showed that: (1) there was a nonsignificant increase temporally, while there was a significant spatial increase that accounted for $63.26 \%$ of the total area and was distributed in the north, west, and south of the QTP. A significant decrease was concentrated southeast of the QTP. (2) Average NDVI values for the main vegetation types in the QTP were broadleaf forest $>$ coniferous forest $>$ shrub $>$ meadow $>$ alpine vegetation $>$ grassland $>$ desert. NDVI values of grassland, alpine vegetation, and desert vegetation had a significant linear increase, while NDVI for shrub, coniferous, and broadleaf forest decreased non-significantly. (3) The correlation coefficients between NDVI and temperature were spatially distributed in a north-south direction with latitudinal zonal characteristics. The correlation coefficients between NDVI and precipitation were distributed in an east-west direction with dry-humidity zonal characteristics. The study concluded that with the lack of hydrothermal conditions in the northern part of the QTP, NDVI increased significantly, while there was a significant decrease in areas with sufficient hydrothermal conditions.
\end{abstract}

Keywords: NDVI, climate change, vegetation type, correlation relationship, Qinghai-Tibet Plateau

\section{Introduction}

Global warming and its environmental effects are major issues in contemporary global environmental change research. Affected by global and regional

*e-mail:wht432@xust.edu.cn warming, the Qinghai-Tibet Plateau (QTP), considered the "Third Pole" in addition to the Antarctic and the Arctic, is undergoing complex changes in its surface natural geography [1-3]. Vegetation is the primary link between surface materials and energy cycles, and the study of temporal and spatial changes and response processes in the QTP under climate warming is of great significance in understanding the response of terrestrial ecosystems to global and regional climate change. 
The normalized difference vegetation index (NDVI) is a data set that has high temporal and multi-spatial resolutions. Obtained by remote sensing, NDVI provides strong support for the study of global and regional vegetation ecosystem changes [4-5]. NDVI-based research on QTP has focused on four aspects: (1) the spatial and temporal changes of vegetation ecosystems and their response to climate change; (2) The response of vegetation ecosystems to climate change and human activities; (3) Vegetation ecosystem function changes, especially vegetation carbon sink functions; and (4) Vegetation phenology changes.

Early research on the spatial and temporal changes of vegetation was based on the global inventory modelling and mapping studies (GIMMS) NDVI data (1982-2006 or 1982-2013), the moderate resolution imaging spectroradiometer (MODIS) NDVI (since 2000), and SPOT NDVI (since 1999) in the QTP [68], Sanjiangyuan [9], Yarlung Zangbo [10], Tibet Autonomous Region [11], and Qinghai Province [12]. Because the data used had varying temporal and spatial resolutions, changes in vegetation over the same spatial range were different and horizontal comparisons cannot be made. Since that time, different versions of the same data have been produced, such as GIMMS NDVIg and NDVI3g data. Du et al. found that average NDVI3g data values were higher than MODIS NDVI and Landsat NDVI values over the same period [13]. In the second research focus, NDVI, meteorological data, ecological protection policies, and major projects were used to quantitatively distinguish the impacts of climate change and human activities on vegetation ecosystem changes in the QTP [14-17]. However, their conclusions differed. Some studies have argued that climate change is the main controlling factor of vegetation in the QTP, while others believe that climate change and human activities play opposite roles, with time-varying stages and a heterogeneous spatial distribution [18-20]. In the third research focus, the spatial and temporal variability of net primary productivity (NPP) and carbon storage/ carbon sinks in different regions and across different vegetation types in the QTP were described, along with their relationships with climate change and human activities. Those studies indicated that with global warming and the implementation of environmental protection and restoration projects, the vegetation of the QTP improved overall but with some local deterioration. Ecosystem function also improved overall [21-24]. The last research focus has found that QTP vegetation phenology has advanced and the growth period has been prolonged. For the vegetation of the QTP, plant growth and development has increased along with vegetation carbon storage [25-27].

Since the 1980s, the vegetation conditions in the QTP have generally improved but with some deterioration. The increase of glacial meltwater caused by climate warming, the expansion of lake area, the shrinkage of permafrost area and increases in soil temperature provided favorable condonations for the growth and development of vegetation in QTP. Vegetation ecosystem service functions and carbon storage/carbon sinks have been further enhanced. Although research on the vegetation of the QTP is rich and comprehensive, there are still some gaps, especially the spatial characteristics of and differences between vegetation types, and their response to climate change. For example, GIMMS NDVIg from 1982 to 2006 and MODIS NDVI after 2000 have been used to study vegetation change in the QTP [28-30], while the latest GIMMS NDVI3g from 1982 to 2015 provide long-term sequence data.

To establish a scientific basis for environmental protection and restoration in the QTP, this paper will analyze NDVI variability in vegetated ecosystems and across different vegetation types, including their response to climate change, using GIMMS NDVI, temperature, precipitation from 1982 to 2015, and vegetation type. Methods include linear regression modeling, correlation coefficients, partial correlation coefficients, and t-tests.

\section{Material and Methods}

\section{Study Area}

The QTP is located in western China between $74^{\circ} 27^{\prime} \mathrm{E}-104^{\circ} 59^{\prime} \mathrm{E}$ and $27^{\circ} 12^{\prime} \mathrm{N}-38^{\circ} 20^{\prime} \mathrm{N}$, and includes Xinjiang Uygur Autonomous Region, Gansu Province, Sichuan Province, Yunnan Province, Qinghai Province, and Tibet Autonomous Region. This includes the entire Tibet Autonomous Region and Qinghai Province (Fig. 1), with a total land area of approximately $259.82 \times 10^{4} \mathrm{~km}^{2}$. The south of the QTP is along the southern margin of the Himalayas, the Kunlun Mountains, Altun Mountains, and the northern edge of the Qilian Mountains are to the north, Pamirs and the Karakoram Mountains are to the west, and to the east is the western section of the Qinling Mountains and the Loess Plateau. The elevation of the QTP is between $3000 \mathrm{~m}$ and $5000 \mathrm{~m}$ with an average elevation of 4000 $\mathrm{m}$. The QTP is called the "Roof of the World" and can be divided into six parts: the northern Tibetan Plateau, the southern Tibet Valley, Qaidam Basin, the Qilian Mountains, the Qinghai Plateau, and the Sichuan-Tibet Alpine Valley.

The climate of the QTP is a unique plateau climate with strong solar radiation, long sunshine hours, low average temperature, low annual temperature accumulation, large temperature differentials, long dry and cold winters, and cool and rainy summers. The annual average temperature drops from $20^{\circ} \mathrm{C}$ to below $6^{\circ} \mathrm{C}$ from south to north and annual precipitation decreases from $2000 \mathrm{~mm}$ to less than $50 \mathrm{~mm}$. The QTP is the birthplace of many rivers in East Asia, Southeast Asia, and South Asia, such as the Yellow River, the Yangtze River, the Lancang River, and the Yarlung Zangbo River. In addition, the QTP is also a region with 


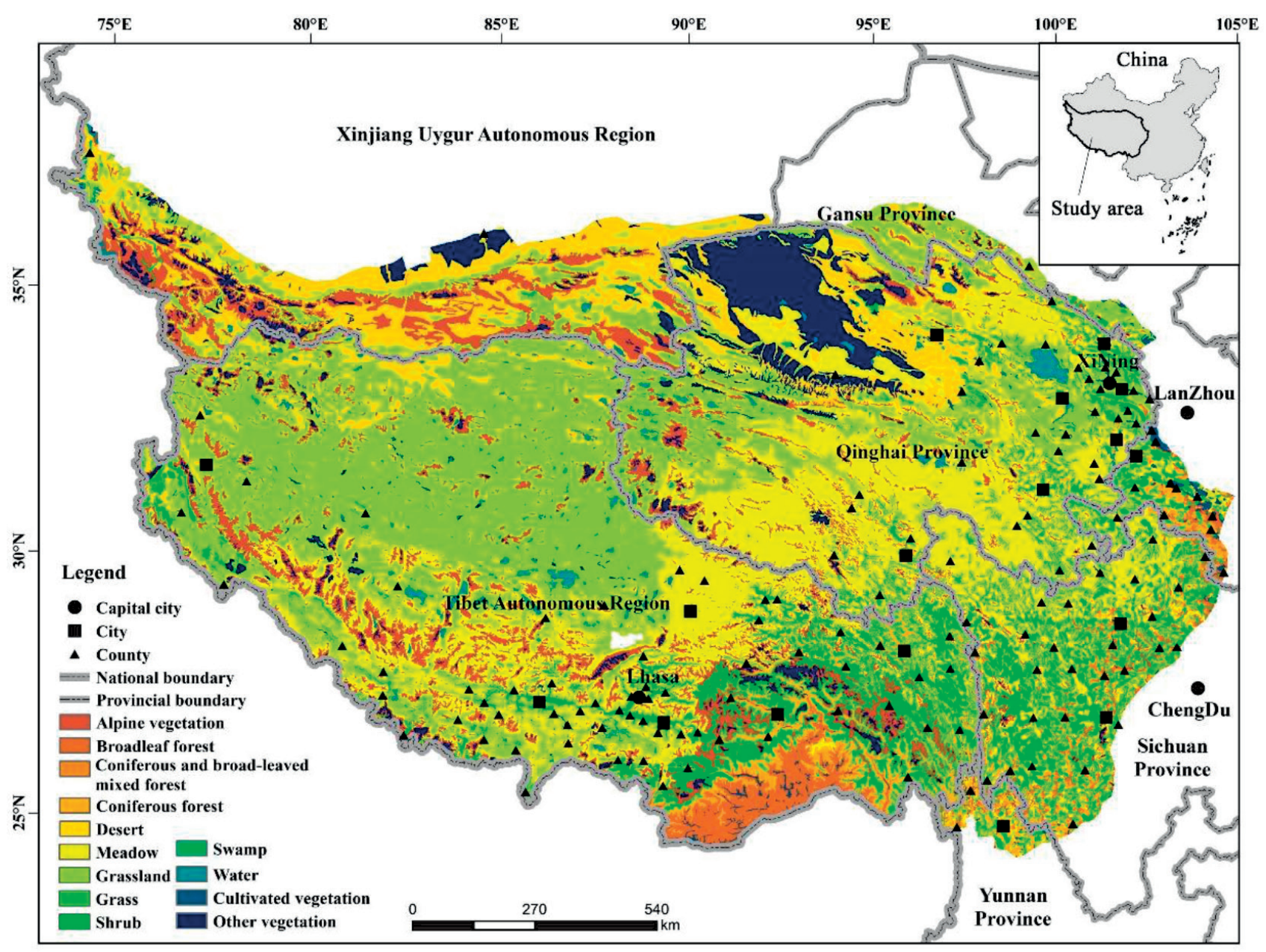

Fig. 1. Study area.

densely distributed lakes in China, including Qinghai, Selin, Namu, Eling, and Bangong Lakes.

There are various types of vegetation in the QTP, including coniferous forest, coniferous and broadleaved mixed forest, broadleaf forest, shrub, desert, grassland, grass, meadow, swamp, alpine vegetation, cultivated vegetation, and other vegetation. Among them, grasslands cover the widest area, accounting for $27.76 \%$ of the total area, followed by meadows $(25.32 \%)$, alpine vegetation and shrubs $(11.26 \%$ and $10.25 \%$, respectively), and other vegetation types (less than $10 \%)$. With global warming, glacier melt and loss are accelerating, the water volume of plateau lakes is increasing, lake water levels are rising, and changes in the fragile terrestrial systems of the QTP have received extensive attention.

\section{Materials}

The data used in this study included: (1) GIMMS NDVI3g (1982-2015). GIMMS NDVI global vegetation index data by National Aeronautics and Space Administration (NASA) were downloaded from http://nex.nasa.gov/nex/ Website. The data were version $3 \mathrm{~g} . \mathrm{vi}$ and compressed in .ncf format. GIMMS NDVI data with a temporal resolution of $15 \mathrm{~d}$ and a spatial resolution of $8 \mathrm{~km}$ were decompressed, projected, and resampled using MATLAB software. The monthly GIMMS NDVI data were calculated from the $15 \mathrm{~d}$ data using the mean method and annual GIMMS NDVI data from 1982 to 2015 were calculated from monthly data by the maximum value composition (MVC) method. Annual GIMMS NDVI data were resampled to $1 \mathrm{~km}$ resolution to analyze spatial and temporal changes and their relationship with temperature and precipitation. (2) Spatial interpolation data for temperature and precipitation (1982-2015). The data were generated using Australian ANUSPLIN interpolation software with a $1 \mathrm{~km}$ resolution of $1 \mathrm{~km}$ from daily observations at more than 2400 meteorological stations across China. (3) Vegetation type data. The data were obtained by digitizing a 1:1 000000 Chinese Vegetation Atlas [31], with a $1 \mathrm{~km}$ resolution. (4) Vector boundary for the QTP. Among the above data, sources (2), (3) and (4) were collected from the Resource and Environment Data Cloud Platform (http://www.resdc.cn). Using the vector boundary for the QTP, annual GIMMS NDVI data from 1982 to 2015 , annual interpolation data for temperature and precipitation, and vegetation type data were obtained. 


\section{Methods}

\section{Linear Regression Model}

Taking NDVI as the dependent variable $(y)$, and the year as the independent variable $(x)$, the linear regression model for NDVI and year was calculated using the least squares method. The formula is [32]:

$$
\begin{gathered}
y=a x+b \\
a=\frac{\sum_{i=1}^{n} x_{i} y_{i}-\frac{1}{n}\left(\sum_{i=1}^{n} x_{i}\right)\left(\sum_{i=1}^{n} y_{i}\right)}{\sum_{i=1}^{n} x_{i}^{2}-\frac{1}{n}\left(\sum_{i=1}^{n} x_{i}\right)^{2}} \\
b=\bar{y}-a \bar{x}
\end{gathered}
$$

...where, $a$ is the coefficient (rate of change), and $b$ is a constant. $\bar{y}$ and $\bar{x}$ are averages for NDVI and year of 1982-2015, respectively. After the linear regression model was obtained, significance testing was performed using the $F$-test. The formula is [32]:

$$
\begin{gathered}
F=\frac{U}{Q /(n-2)} \\
U=b^{2} \sum_{i=1}^{n}\left(x_{i}-\bar{x}\right)^{2} \\
Q=\sum_{i=1}^{n}\left(y_{i}-y^{\prime}\right)^{2}
\end{gathered}
$$

...where, $y^{\prime}$ is the fitted value of $y$ calculated by the linear regression model. After calculating the $F$ value, at $\alpha=0.05$, the critical value of $F$ was identified as 4.15 from the $F$ distribution table. If $F>4.15$, the linear regression equation was significant, otherwise it was not significant.

\section{Correlation and Partial Correlation Analysis}

Correlation analysis was used to analyze the relationships between NDVI and temperature and precipitation. The correlation coefficient was used to analyze the correlations between two independent variables, such as those between NDVI and temperature, and NDVI and precipitation. The formula is [32]:

$$
r_{x y}=\frac{\sum_{i=1}^{n}\left[\left(x_{i}-\bar{x}\right) \times\left(y_{i}-\bar{y}\right)\right]}{\sqrt{\sum_{i=1}^{n}\left(x_{i}-\bar{x}\right)^{2}} \times \sqrt{\sum_{i=1}^{n}\left(y_{i}-\bar{y}\right)^{2}}}
$$

Where, $r_{x y}$ is the correlation coefficient with a value between -1 and 1 . The closer the absolute value of $r_{x y}$ is to 1 , the stronger the correlation, and vice versa. $\bar{y}$ and $\bar{x}$ are the average values of $x$ and $y$, respectively. After calculating the correlation coefficient, when $\alpha=0.05$, the critical value of the correlation coefficient threshold was 0.3494 in the correlation coefficient threshold distribution table. If $\left|r_{x y}\right|>0.3494$, the correlation was significant, otherwise it was not significant.

The partial correlation coefficient was used to analyze the relationship between any two variables of NDVI, temperature, and precipitation. Assuming that one of the variables was unchanged, the correlation between the other two variables was calculated as [32]:

$$
r_{12 \cdot 3}=\frac{r_{12}-r_{13} \times r_{23}}{\sqrt{\left(1-r_{13}^{2}\right) \times\left(1-r_{23}^{2}\right)}}
$$

...where, $r_{12 \cdot 3}$ is the partial correlation coefficient for variables 1 and 2 when variable 3 was unchanged. $r_{12}, r_{13}$ and $r_{23}$ are the correlation coefficients for variables 1 and 2, variables 1 and 3, and variables 2 and 3 , respectively. The partial correlation coefficients were tested using the $t$-test method and the formula is [32]:

$$
t=\frac{r_{12 \cdot 3}}{\sqrt{1-r_{12 \cdot 3}^{2}}} \sqrt{n-m-1}
$$

...where, $n$ is the number of samples and $m$ is the number of independent variables, while the other variables are the same as above. After the $t$ value was calculated, when $\alpha=0.05$, the critical value for $t$ was 2.042 from the $t$ distribution table. If $t>2.042$, the partial correlation was significant, otherwise it was not significant.

\section{Results}

\section{Temporal and Spatial Changes in NDVI over the QTP}

\section{Temporal Change}

The main vegetation types on the QTP (grassland, meadow, alpine vegetation, and shrub) had the lowest average NDVI values. The annual average from 1982-2015 was only 0.3568 . The annual average NDVI also increased non-significantly during the study period (Fig. 2a). The lowest annual average NDVI was 0.3466 in 2003 and the highest was 0.3637 in 2012. The difference between the two was small, only 0.0161 .

According to NDVI anomaly variability in the QTP, NDVI change could be divided into four stages (Fig. 2b). During the first stage from 1982 to 1987, 
the annual average NDVI was 0.3521. Compared with the annual average from 1982 to 2015, anomalies were negative and NDVI values in the first stage were lower than the average over the whole period from 1982 to 2015. During the second stage from 1988 to 2000, the annual average was 0.3589 and anomalies were primarily positive. There were eight years of positive anomaly values and five years when they were negative. NDVI variability during this stage was more pronounced. During the third stage from 2001 to 2008, the annual average was 0.3537 , which was the lowest of the four stages. Aside from positive anomalies in 2002 and 2005 , the other years had negative anomalies. The fourth stage was from 2009 to 2015 and the annual average NDVI was 0.3603 . Aside from the negative anomaly in 2014, the other years were positive. The improvement in NDVI during this stage may have been related to the ecological security barrier project in the QTP that began in 2008 .

Overall, annual average NDVI values during the first and third stages were lower than values from 1982 to 2015 , and these two stages reflected relatively poor vegetation. In the second and fourth stages, NDVI increased, but the second stage showed an increase in NDVI. The fourth stage indicated that NDVI in the QTP increased and the overall values were relatively high.
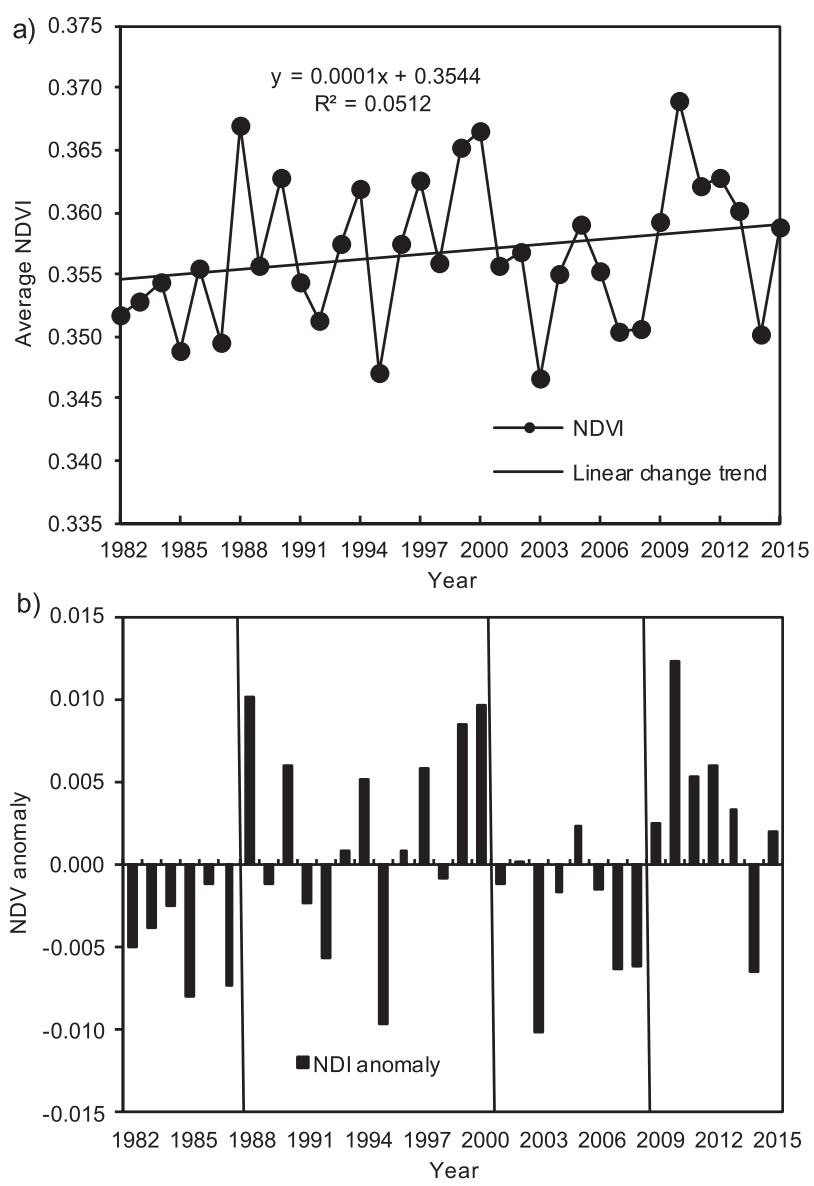

Fig. 2. Change in annual average NDVI a) and anomalies b).

\section{Spatial Change}

The spatial distribution of NDVI change from 1982 to 2015 (Fig. 3a) revealed a linear increase that accounted for $85.87 \%$ of the total area (excluding water bodies and areas with no data). The annual average change rate of NDVI primarily ranged from -0.002 and $<0.004$, accounting for $97.80 \%$ of the total area, in which the range from -0.002 to 0 accounted for $13.07 \%$, from 0 to 0.002 accounted for $64.40 \%$, and from 0.002 to 0.004 accounted for $20.33 \%$. From 1982 to 2015 , areas with higher rates of NDVI increase were concentrated in the southern, eastern, and northeastern marginal areas of the Qaidam Basin in Qinghai Province, and southern Tibet, while the areas with NDVI decreases were concentrated along the eastern edge of the QTP in Sichuan Province, and a small part was distributed in eastern Tibet.

Using the linear change rate and $F$-test results for NDVI from 1982 to 2015, the change trend was divided into four types: non-significant decrease, significant decrease, non-significant increase, and significant increase (Fig. 3b). NDVI increased in the northern, western, and southern parts of the plateau, such as the western and northern parts of Qinghai Province, southern Xinjiang, and western and southern Tibet, accounting for $63.26 \%$ of the total area. Due to the distribution of provincial capitals, cities, and counties
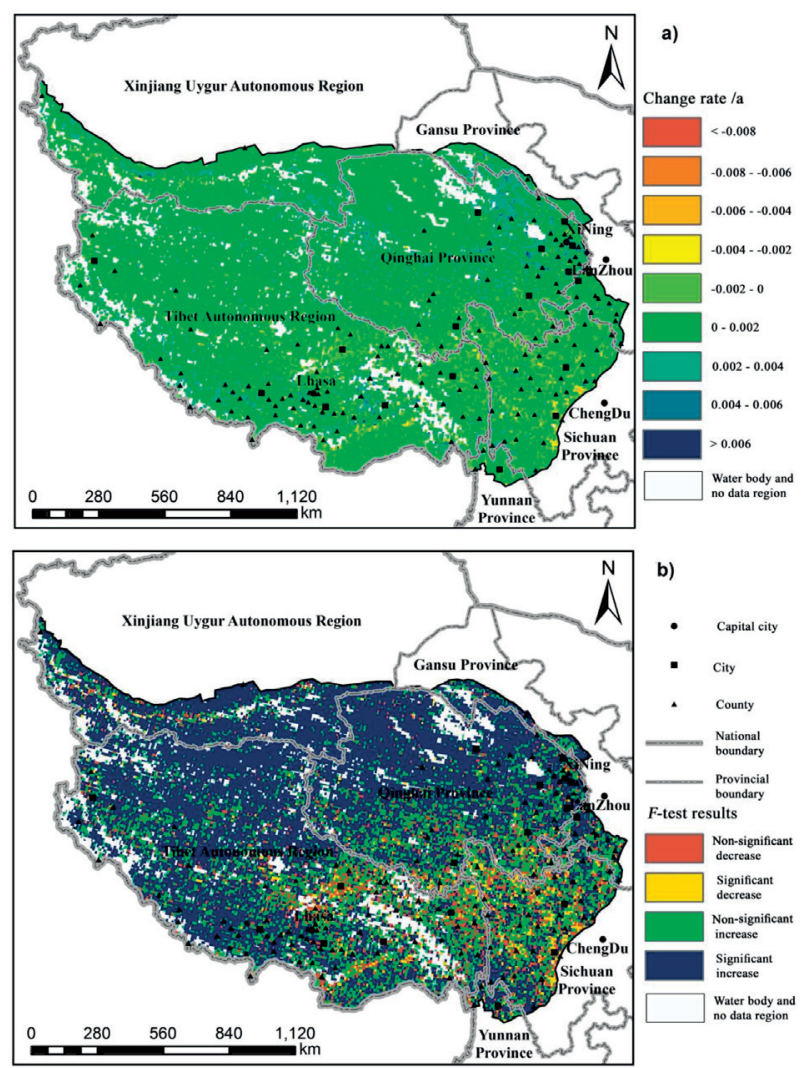

Fig. 3. Spatial distribution of NDVI change rate a) and F-test results b). 
in the QTP, it was known that areas with significant increases were distributed where there were few cities at all levels. It was assumed that human activities in the region were relatively sparse and vegetation changes were mainly influenced by the climate. Improving hydrothermal conditions were conducive to the growth and development of vegetation and NDVI increased. In other areas, vegetation growth and development were limited and NDVI decreased. Areas with significant NDVI decreases were concentrated in the southern part of the plateau where cities were densely distributed, such as eastern Tibet, southern Qinghai,
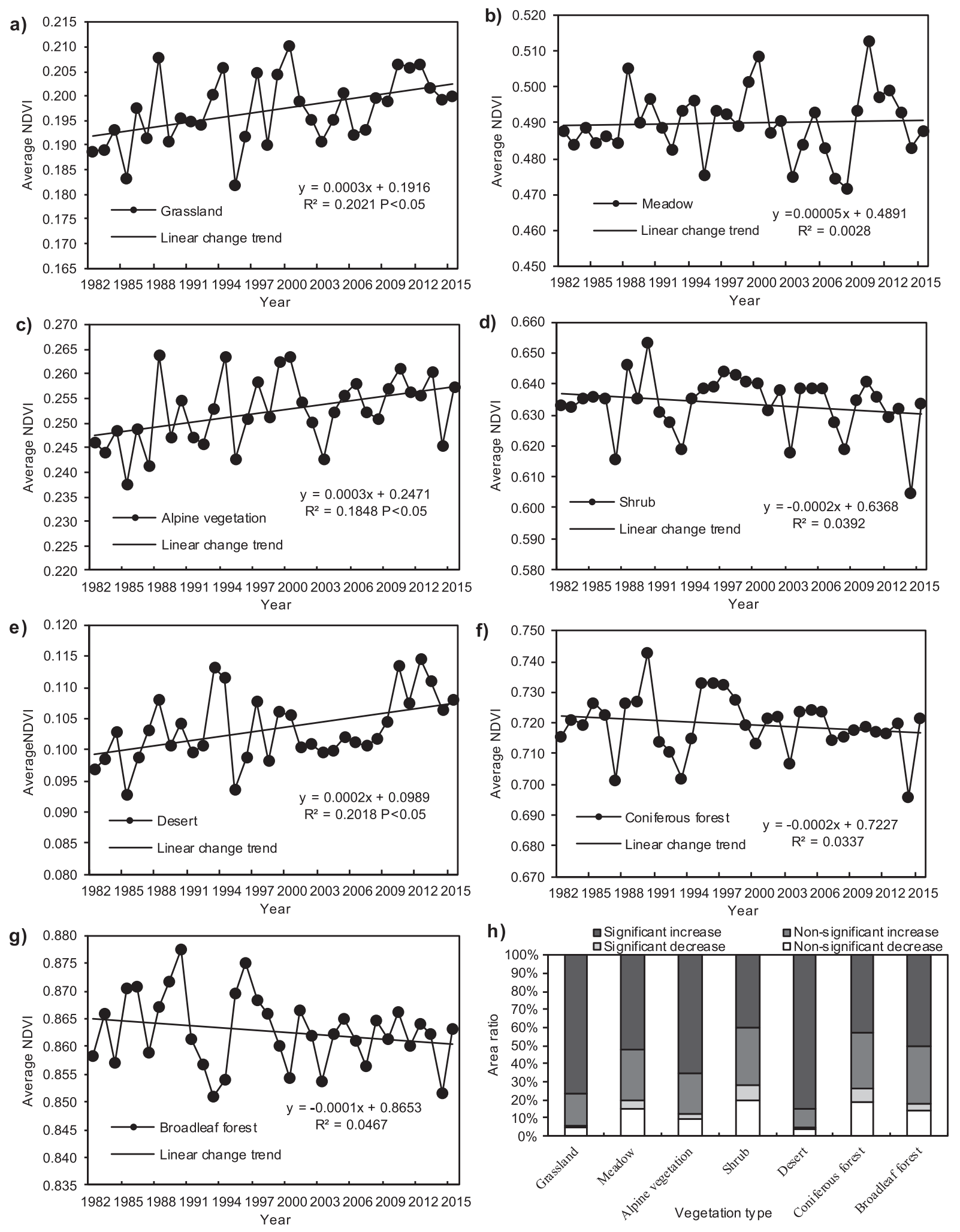

Fig. 4. Change processes (a-g) and the ratios of NDVI change rates $\mathrm{h}$ ) for different vegetation types. 
western Sichuan, and the border of the three provinces. Significant and non-significant decreases, as well as non-significant increases, were distributed in those areas with respective proportions of $3.45 \%, 10.68 \%$, and $22.61 \%$. With global warming, the average temperature of the QTP increased, which provided favorable conditions for vegetation growth and development that led to a large-scale significant increase in NDVI from 1982 to 2015.

\section{NDVI Changes Across Different Vegetation Types}

The primary vegetation types in the QTP (grassland, meadow, alpine vegetation, shrub, desert, coniferous forest, and broadleaf forest) accounted for $91.45 \%$ of the total area. Using the spatial distribution data for these types corresponding NDVI values were extracted and the temporal and spatial change results calculated by the $F$-test were analyzed to better understand the dynamic changes in vegetation (Fig. 4).

Among the seven main vegetation types, average NDVI values for broadleaf forest from 1982 to 2015 were the highest, reaching 0.8628 , followed by coniferous forest vegetation at 0.7197 . The average values for shrub, meadow, and alpine vegetation were $0.6335,0.4899$, and 0.2524 , respectively. Average NDVI values for grassland and desert were the lowest at only 0.1972 and 0.1032 , respectively. NDVI values for grassland, meadow, alpine vegetation, and desert vegetation types increased over time. Significant increases occurred in grassland, alpine vegetation, and desert vegetation types with showed a significant increasing process, and the linear rates of increase were $0.0003 / \mathrm{a}, 0.0003 / \mathrm{a}$, and $0.0002 / \mathrm{a}$, respectively (Fig. 4a, Fig. 4b, Fig. 4c and Fig. 4e). As global average temperatures rose, the average temperature in the QTP also gradually increased and the thermal conditions required for the growth of plateau vegetation gradually improved, resulting in an increase in overall vegetation. NDVI values for shrub, coniferous and broadleaf forest vegetation decreased, but they were non-significant (Fig. 4d, Fig. 4f and Fig. 4g). F-test results showed that seven vegetation types on the QTP showed significant NDVI increases during 1982-2015, especially on the areas with significantly increased NDVI for desert, grassland, alpine vegetation, meadow and broadleaf forest, the increase reached $85.36 \%, 76.63 \%, 65.43 \%$, $51.93 \%$ and $50.69 \%$, respectively (Fig. 4h) .

\section{NDVI Response to Climate Change}

Temperature and precipitation are important indicators for climate. The response of NDVI to temperature and precipitation changes could help describe the impacts of climate change on terrestrial vegetation ecosystems of the QTP [33]. The correlation coefficients, partial correlation coefficients, and $t$-test results were divided into four types: significant negative correlation, negative correlation, positive correlation, and significant positive correlation (Fig. 5).

Temperature is a characteristic indicator of heat. As the global climate warmed, temperatures in the QTP also increased, providing more thermal resources for vegetation growth. There was a latitudinal spatial distribution of the correlation coefficients between NDVI and temperature, and positive correlation coefficients were concentrated in the northern part of the QTP (Fig. 5a). The spatial distribution of the correlation coefficients between NDVI and precipitation was from dry to wet in the east-west direction, and positive correlations with north-south direction were concentrated in the central eastern and the central western regions (Fig. 5b). The correlation coefficients and partial correlation coefficient $t$-test results between NDVI and temperature in the QTP from 1982 to 2015 were mainly positive and the spatial distribution was relatively uniform in a north-south distribution. Significant positive correlations were distributed in Qinghai Province in the northern QTP and the border areas of Qinghai, Xinjiang, and Tibet. Significant negative correlations were concentrated from west to east in the central and southern parts of the QTP, mainly in Tibet and Sichuan Province, and small areas were found along the border between southeast Qinghai Province and Sichuan Province, accounting for $6.46 \%$ and $7.59 \%$, respectively (Fig. 5c, Fig. 5e). The QTP had fewer thermal resources, higher temperatures, and increased caloric resources that improved vegetation stability and development. However, the negative correlations between NDVI and temperature reflected that NDVI in those areas did not increase with temperature, but rather decreased. The driving factors of this process are still unknown and need to be studied separately.

The correlations and partial correlations between NDVI and precipitation were lower than those between NDVI and temperature. However, the correlation coefficients between NDVI and precipitation and the partial correlation coefficient $t$-test results were still mainly positive and the spatial distribution was consistent from east to west (Fig. 5d, Fig. 5f). Among them, significant positive correlations were distributed in the northern part of Qinghai Province, south central and eastern Tibet, and the junction between Tibet and Xinjiang. Significant negative correlations were found in relatively small areas in the southeastern part of Qinghai Province and western, central, and southern Tibet, accounting for $1.80 \%$ and $1.92 \%$ of the total area, respectively. Significant correlations between NDVI and temperature and precipitation in the QTP and the proportion of significant partial correlations indicated that, under the influence of temperature or precipitation change, areas with significant negative correlations and significant negative partial correlations between NDVI and temperature increased, while the significant positive correlations and significant partial correlations decreased. This means that temperature had a negative cross-effect on the correlations between NDVI 


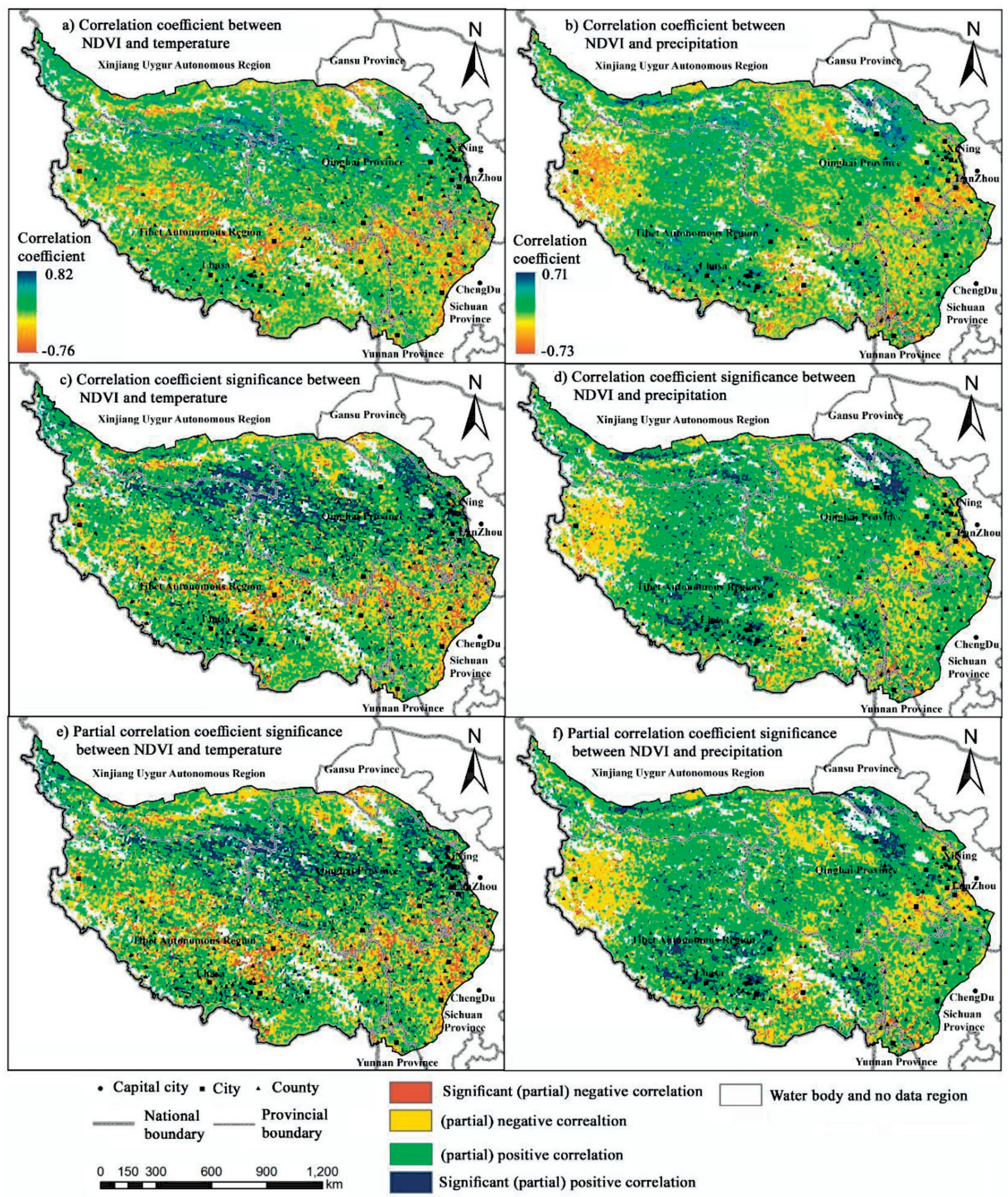

Fig. 5. Spatial distribution of correlation coefficients ( $a, b)$, correlations (c, d) and partial correlation relationship (e, f) between NDVI and temperature, precipitation.

and precipitation, and precipitation had a negative cross-effect on the correlations between NDVI and temperature, leading to increases in significant negative correlations and decreases in positive correlations.

\section{Discussion}

NDVI plays an important role in reflecting global climate change and characterizing surface vegetation ecology and productivity. The results of prior NDVI research in the QTP were fairly consistent with the results of this study. It showed that due to global warming, NDVI and net primary productivity increased from the 1980s $[18,34]$. However, due to the different length of the NDVI dataset used, the spatial change distribution was not the same. The GIMMS NDVI data used in this paper covered a long time series (from 1982) but with resolution was lower, while the MODIS NDVI data had higher resolution and a shorter time 
series (from 2000) [8]. A combination of the two could meet the need for a long-term temporal sequence and better spatial detail.

Yao et al. proposed three modes of interaction between the modern westerly winds and the Indian monsoon on the QTP: the Indian monsoon mode, the westerly mode, and the transitional mode [35]. Under the influence of the Indian monsoon, lakes in the Yarlung Zangbo River Basin in the south of the QTP generally shrink, and lakes in the northern Qiangtang Plateau generally grow significantly [36]. This study showed that significant increases in NDVI from 1982 to 2015 were mainly distributed in the northern and west of the plateau controlled by the westerly winds, while the decreasing vegetation in the southeastern part of the plateau was controlled by the Indian monsoon. This confirmed the influence of the Indian monsoon and westerly wind modes in the QTP in the past 30 years. Global warming produced significant differences in NDVI variability across different parts of the QTP. NDVI declined in the southeastern region where hydrothermal conditions were abundant, and increases in NDVI occurred in the northern part of the QTP where hydrothermal conditions were relatively poor. The change of NDVI in different vegetation type response to air temperature and precipitation changes in the QTP was also obvious. Higher values for broadleaf forest, coniferous forest, shrub, and meadow distributed in the southeast of the QTP actually declined or slightly

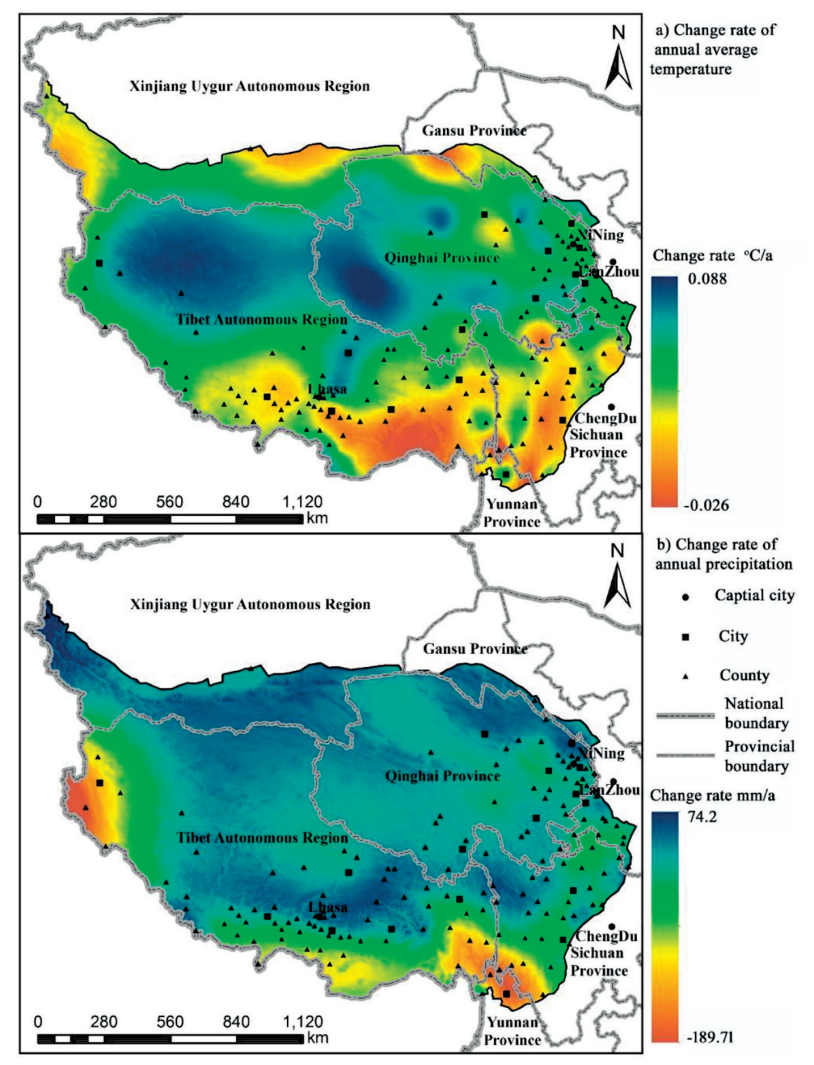

Fig. 6. Spatial distribution of annual average temperature and precipitation change rates (1982-2015). increased (meadow) in the QTP from 1982 to 2015, while NDVI values for vegetation types with lower average values, such as alpine vegetation, grassland, and desert distributed in the north-central and western parts of the QTP, showed a significant increase. This reflects that during the study period, the abundance of vegetation types with lower NDVI values were higher than those with higher NDVI. This implies that climate change had differential effects on the vegetation ecosystems of the QTP. For example, relatively fragile alpine vegetation, grassland, and desert vegetation ecosystems improved, while broadleaf forest, coniferous forest, and shrub showed signs of deterioration, which needs to be taken seriously.

Zheng et al. studied increases in temperature and precipitation in the QTP, finding that the drywet boundary has shifted to the northwest [37]. From 1982 to 2015 , the spatial distribution of annual average temperature and annual precipitation change in the QTP reflected an increase in those variables. Only a small area in the southern and western part of the QTP showed a decline (Fig. 6). That is, most of the QTP experienced a warm and humid trend, which provided favorable conditions for vegetation growth. NDVI values significantly increased for alpine vegetation, grassland, and desert vegetation in the QTP in areas with fragile vegetation and low NDVI [7-8, 28, 30,]. To determine whether the increase or decrease in NDVI for different vegetation types was related to cyclical climate change, it was also necessary to set the NDVI periodic fluctuation threshold to identify whether the trends from the 1980s were within the range of vegetation fluctuations caused by climate change. If NDVI only fluctuates cyclically with climate change, there is no need to investigate this further, but if it exceeds the range of cyclical fluctuations, it needs to be taken seriously.

\section{Conclusions}

(1) NDVI in the QTP from 1982 to 2015 increased non-significantly overall, where the periods from 19821987 and 2001-2008 had negative anomalies, and 19882000 and 2009-2015 had positive anomalies. Spatial variability mainly increased in the north, west, and south of the QTP, such as the western and northern parts of Qinghai Province, southern Xinjiang, and western and southern Tibet, accounting for $63.26 \%$ of the total area. Significant decreases were concentrated in the southeastern part of the QTP, such as the eastern part of Tibet, the southern part of Qinghai Province, the western part of Sichuan Province, and the border areas of the three provinces, accounting for only $3.45 \%$ of the total area.

(2) Average NDVI values for the main vegetation types in the QTP were: broadleaf forest>coniferous forest $>$ shrub $>$ meadow $>$ alpine vegetation $>$ grassland $>$ desert, in which NDVI for grassland, alpine vegetation, 
and desert vegetation had significant linear increases. The meadow vegetation type had a non-significant increase, while NDVI for shrub, coniferous, and broadleaf forest vegetation had non-significant decreases. This process may reflect the spatial variation of climate change impacts on QTP vegetation. Areas that lacked hydrothermal conditions in the northern part of the QTP had a significant increase in NDVI, while areas with sufficient hydrothermal conditions in the southeastern part of the QTP had a significant decrease.

(3) The correlation coefficients between NDVI and temperature of the QTP were spatially distributed in a north-south direction with latitudinal zonal characteristics. Significant positive correlations were distributed in the north-central areas of the QTP, accounting for $15.80 \%$, and significant negative correlations were distributed in the south-central parts, accounting for $6.46 \%$. The correlation coefficients between NDVI and precipitation were distributed from east to west and had dry and humid zonal characteristics. Significant positive correlations were distributed in the middle of the QTP, accounting for $9.12 \%$, and significant negative correlations were distributed on the east and west sides of the QTP, accounting for $1.80 \%$.

\section{Acknowledgements}

This work was supported by the National Natural Science Foundation of China (41501571, 41807503), the Scientific Research Program Funded by the Shaanxi Provincial Education Department (18JK0524), and the Key Research and Development Program of Shaanxi (2018ZDXM-GY-027). We thank Dr. Li Pengfei for his linguistic assistance during the preparation of this manuscript.

\section{Conflict of Interest}

The authors declare no conflict of interest.

\section{References}

1. CHEN D.L., XU B.Q., YAO T.D., GUO Z.T., CUI P., CHEN F.H., ZHANG R.H., ZHANG X.Z., ZHANG Y.L., FAN J., HOU Z.Q., ZHANG T.H. Assessment of past, presents and future environmental changes on the Tibetan Plateau. Chinese Science Bulletin, 60 (32), 3025, 2015 [In Chinese with English Abstract].

2. ZHANG X.Z., YANG Y.P., PIAO S.L., BAO W.K., WANG S.P., WANG G.X., SUN H., LUO T.X., ZHANG Y.J., SHI P.J., LIANG E.Y., SHEN M.G., WANG J.S., GAO Q.Z., ZHANG Y.L., OUYANG H. Ecological change on the Tibetan Plateau. Chinese Science Bulletin, 60 (32), 3048, 2015 [In Chinese with English Abstract].

3. ZHANG R.H., SU F.G., JANG Z.H., GAO X.J., GUO D.L., NI J., YOU Q.L., LAN C., ZHOU B.T. An overview of projected climate and environmental changes across the Tibetan Plateau in the $21^{\text {st }}$ century. Chinese Science
Bulletin, 60 (32), 3036, 2015 [In Chines with English Abstract].

4. WANG X.Y., YI S.H., WU Q.B., YANG K., DING Y.J. The role of permafrost and soil water in distribution of alpine grassland and its NDVI dynamics on the Qinghai-Tibetan Plateau. Global and Planetary Change, 147, 40, 2016.

5. JANG Y.Y., DU W.T., HUANG J., ZHAO H.Z., WANG C.F. Analysis of vegetation changes in the Qilian Mountains during 2000-2015. Journal of Glaciology and Geocryology, 39 (5), 1130, 2017 [In Chines with English Abstract].

6. LI Y.F., SUN, J. Temporal and spatial variation of NDVI in Tibetan Plateau from 1982 to 2008. Journal of Yunnan Agricultural University, 30 (5), 790, 2015 [In Chines with English Abstract].

7. MENG M., NIU Z., MA C., TIAN H.F., PEI J. Variation trend of NDVI and response to climate change in Tibetan Plateau. Research of Soil and Water Conservation, 25 (3), 360, 2018 [In Chines with English Abstract].

8. ZHUOGA, CHEN S.R., ZHOU B. Spatio-temporal variation of vegetation coverage over the Tibetan Plateau and its responses to climatic factors. Acta Ecologica Sinica, 38 (9), 3208, 2018 [In Chines with English Abstract].

9. LIU X.F., ZHANG J.H., ZHU X.F., PAN Y.Z., LIU Y.X., ZHANG D.H., LIN Z.H. Spatiotemporal in vegetation coverage and its driving factors in the ThreeRiver Headwaters Region during 2000-2011. Jounal of Geographical Sciences, 24 (2), 288, 2014.

10. GUO B., ZHOU Y., WANG S.X., TAO H.P. The relationship between normalized difference vegetation index (NDVI) and climate factors in the semi-arid region: a case study in Yalu Tsangpo River basin of Qinghai-Tibet Plateau. Journal of Mountain Science, 11 (4), 926, 2014.

11. SUN J., QIN X.J. Precipitation and temperature regulate the seasonal changes of NDVI across the Tibetan Plateau. Environmental Earth Sciences, 75 (4), 1, 2016.

12. LIU S.L., ZHANG Y.Q., CHENG F.Y., HOU X.Y., ZHAO S. Response of grassland degradation to drought at different time-scale in Qinghai Province: spatio-temporal characteristics, correlation, and implications. Remote. Sensing, 9 (12), 1329, 2017.

13. DU J.Q., WANG Y.H., SHI H.D., FANG S.X., HE P., LIU W.L., YIN J.Q. Performance evaluation of GIMMS NDVI3g and GIMMS NDVIg based on MODIS and Landsat in Tibetan Plateau. Transactions of the Chinese Society of Agricultural Engineering, 32 (22), 192, 2016 [In Chines with English Abstract].

14. CAI H.Y., YANG X.H., XU X.L. Human-induced grassland degradation/restoration in the central Tibetan Plateau: the effects of ecological protection and restoration projects. Ecological Engineering, 83, 112, 2015.

15. WANG G.J., GILLESPIE A.R., LIANG S.H., MUSHKIN A., WU Q.B. Effect of the Qinghai-Tibet Railway on vegetation abundance. Int. J. Remote. Sens., 36 (19/20), 5222, 2015.

16. LU Q.S., NING J.C., LIANG F.Y., BI X.L. Evaluating the effects of government policy and drought from 1984 to 2009 on rangeland in the Three Rivers Source Region of the Qinghai-Tibet Plateau. Sustainability, 9 (6), 1033, 2017.

17. NIU F.J., YIN G.A., LUO J., LIN Z.J., LIU M.H. Permafrost distribution along the Qinghai-Tibet engineering corridor, China using high-resolution statistical mapping and modeling integrated with remote sensing and GIS. Remote Sensing, 10 (2), 215, 2018.

18. CHEN B.X., ZHANG X.Z., TAO J., WU J.S., WANG J.S., SHI P.L., ZHANG Y.J., YU C.Q. The impact of climate change and anthropogenic activities on alpine grassland 
over the Qinghai-Tibet Plateau. Agricultural and Forest Meteorology, 189/190, 11, 2014.

19. YIN F., DDENG X.Z., JIN Q., YUAN Y.W., ZHAO C.H. The impacts of climate change and human activities on grassland productivity in Qinghai Province, China. Frontiers of Earth Science, 8 (1), 93, 2014.

20. HUANG K., ZHANG Y. J., ZHU J.T., LIU Y.J., ZU J.X., ZHANG J. The influences of climate change and human activities on vegetation dynamics in the Qinghai-Tibet Plateau. Remote Sensing, 8 (10), 2016.

21. ZHANG L., GUO H.D., WANG C.Z., JI L., LI J., WANG K., DAI L. The long-term trends (1982-2006) in vegetation greenness of the alpine ecosystem in the Qinghai-Tibetan Plateau. Environ. Earth. Sci., 72 (6), 1827, 2014.

22. QIN X.J., SUN J., LIU M., LU X.Y. The impact of climate change and human activity on net primary production in Tibet. Polish Journal of Environmental Studies, 25 (5), 1, 2016.

23. WANG Z.W., WANG Q., WU X.D., ZHAO L., YUE G.Y., NAN Z.T., WANG R.C., YI S.H., ZOU D.F., QIN Y., WU T.H., SHI J.Z. Vegetation changes in the permafrost regions of the Qinghai-Tibetan Plateau from 1982-2012: different responses related to geographical locations and vegetation types in high-altitude areas. Plos One, 12 (1), e0169732, 2017.

24. HUANG L., CAO W., XU X.L., FAN J.W., WANG J.B. The ecological effects of ecological security barrier protection and construction project in Tibet Plateau. Journal of Natural Resources, 33 (3), 398, 2018 [In Chines with English Abstract].

25. SONG Y., JIN L., WANG H.B. Vegetation changes along the Qinghai-Tibet Plateau engineering corridor since 2000 induced by climate change and human activities. Remote Sensing, 10 (1), 95, 2018.

26. ZHANG Q., KONG D.D., SHI P.J., SINGH V.P., SUN P. Vegetation phenology on the Qinghai-Tibetan Plateau and its response to climate change (1982-2013). Agricultural and Forest Meteorology, 248, 408, 2018.

27. ZHAO Z.H., LIU G.H., MOU N.X., XIE Y.C., XU Z.R., LI Y. Assessment of carbon storage and its influencing factors in Qinghai-Tibet Plateau. Sustainability, 10 (6), 1864, 2018.

28. ZHOU T., ZHANG Y.S., GAO H.F., ZHANG T., MA Y.Z. Relationship between vegetation index and ground surface temperature on the Tibetan Plateau alpine grassland. Journal of Glaciology and Geocryoloy, 37 (1), 58, 2015 [In Chines with English Abstract].

29. WANG Z.W., WU X.D., YUE G.Y., ZHAO L. Spatial and temporal variations in spectrum-derived vegetation growth trend in Qinghai-Tibetan Plateau from 1982 to 2014. Spectroscopy and Spectral Analysis, 36 (2), 471, 2016 [In Chines with English Abstract].

30. LIU Z.Y., ZHANG J., CHEN L. The latest change in the Qinghai-Tibetan Plateau vegetation index and its relationship with climate factors. Climatic and Environmental Research, 22 (3), 289, 2017 [In Chines with English Abstract].

31. Chinese Vegetation Map Editorial Board of Chinese Academy of Science (CVMEBCAS). 1:1 000000 Chinese Vegetation Atlas, Science Press: Beijing, China, 15, 2001 [In Chinese].

32. XU J.H. Quantitative geography, $3^{\text {rd }}$ ed.; Higher Education Press: Beijing, China, 40, 2014 [In Chinese].

33. LU Q., WU S.H., ZHAO D.S. Variations in alpine grassland cover and its correlation with climate variables on the Qinghai-Tibet Plateau in 1982-2013. Scientia Geographica Sinica, 37 (2), 292, 2017 [In Chines with English Abstract].

34. PIAO S.L., TAN K., NAN H.J., CIAIS P., FANG J.Y., WANG T., VUICHARD N., ZHU B. Impacts of climate and $\mathrm{CO}_{2}$ changes on the vegetation growth and carbon balance of Qinghai-Tibetan grasslands over the past decades. Global and Planetary Change, 98/99, 73, 2012.

35. YAO T.D., PIAO S.L., SHEN M.G., GAO J., YANG W., ZHANG G.Q., LEI Y.B., GAO Y., ZHU L.P., XU B.Q., YU W.S., LI S.H. Chained impacts on modern environment of interaction between westerlies and Indian monsoon on Tibetan Plateau. Bulletin of Chinese Academy of Sciences, 32 (9), 976, 2017 [In Chines with English Abstract].

36. LEI Y.B., YANG K., WANG B., SHENG Y.W., BIRD B.W., ZHANG G.Q., TIAN L.D. Response of inland lake dynamics over the Tibetan Plateau to climate change. Climate Change, 125 (2), 281, 2014.

37. ZHENG R., LI D.L. Decadal changes of the wet and dry climate zone boundaries in the Qinghai-Tibet Plateau during 1971-2011. Journal of Desert Research, 36 (4), 1106, 2016 [In Chines with English Abstract]. 
